\title{
Dealing with Delayed Onset Muscle Soreness (DOMS): Foam Roller or Mechanical Manipulation of Body Tissue
}

\author{
Mohamad Nizam Nazarudin,,", Mohd Firdaus Abdullah", ${ }^{2,3}$, Mohd Radzani Abdul Razak ${ }^{3}$, \\ Abu Yazid Abu Bakar ${ }^{3}$, Denise Koh Choon Lian ${ }^{3}$, Wan Ahmad Munsif Wan Pa ${ }^{3}$ \\ ${ }^{1}$ Faculty of Psychology and Education, Universiti Malaysia Sabah, 88400 Kota Kinabalu, Sabah, Malaysia \\ ${ }^{2}$ Centre For Sports and Exercise Science, Universiti Malaya, Malaysia \\ ${ }^{3}$ Faculty of Education, Universiti Kebangsaan Malaysia, 43600 Bangi, Selangor, Malaysia
}

Received November 29, 2020; Revised March 31, 2021; Accepted April 18, 2021

\section{Cite This Paper in the following Citation Styles}

(a): [1] Mohamad Nizam Nazarudin, Mohd Firdaus Abdullah, Mohd Radzani Abdul Razak, Abu Yazid Abu Bakar, Denise Koh Choon Lian, Wan Ahmad Munsif Wan Pa, "Dealing with Delayed Onset Muscle Soreness (DOMS): Foam Roller or Mechanical Manipulation of Body Tissue," International Journal of Human Movement and Sports Sciences, Vol. 9, No. 3, pp. 383 - 393, 2021. DOI: 10.13189/saj.2021.090301.

(b): Mohamad Nizam Nazarudin, Mohd Firdaus Abdullah, Mohd Radzani Abdul Razak, Abu Yazid Abu Bakar, Denise Koh Choon Lian, Wan Ahmad Munsif Wan Pa (2021). Dealing with Delayed Onset Muscle Soreness (DOMS): Foam Roller or Mechanical Manipulation of Body Tissue. International Journal of Human Movement and Sports Sciences, 9(3), 383 - 393. DOI: 10.13189/saj.2021.090301.

Copyright $\mathrm{C} 2021$ by authors, all rights reserved. Authors agree that this article remains permanently open access under the terms of the Creative Commons Attribution License 4.0 International License

\begin{abstract}
This research focuses on determining the efficacy of sports massage (SM) and foam rolling (FR) to decrease Delayed Onset Muscle Soreness (DOMS) among users of recreational gyms. The goal of this study is to fit the physiotherapist's more efficient technique or techniques to scale back DOMS. SM and FR are two factors that help to illustrate the efficacy of DOMS scale back. Both therapies, SM and FR party, were handled with the selected samples for this analysis. Repeated measure ANOVA was used for testing results on the impact of SM on the range of motion (ROM). Results showed the effect of SM on pain meter supported on three occasions, and the effect of froth rolling on the pain meter on three times. Results suggest that there are not substantially different effects between therapies for all elbow flexion ranges of motion. Both therapies are often used to minimize DOMS due to growth over a 3-fold duration. The researcher has dressed up a couple of the guidelines and ideas required for future studies to be used. Future research should refer to the feminine community to boost the performance.
\end{abstract}

Keywords DOMS, ROM, Sports Massage, Form Roller, Therapies

\section{Introduction}

Massage is widely used for quicker healing, such as muscle injury, during exercise. 45 percent of sport physiotherapy requires injury. Muscle blood flow, lactate clearance [1]. However, FR has become a common procedure to scale back or avoid soft tissue constraints. Individuals use their own weight on [2]. DOMS is the one not to be exposed from exercise or physical activity by requiring eccentric contraction among muscle injury. DOMS also happens after exhaustive exercise during the first 24 to 72 hours. In addition, a variety of physiotherapy methods are also used to alleviate the effects of DOMS, such as SM and compression clothes [3].

This research aims to align the physiotherapist's approach or techniques more efficiently to scale. Massage has been found [4] to have a beneficial effect by minimizing muscle soreness and other DOMS symptoms. Massage will decrease the pressure on the ligament unit of the muscle that affects the visco-elastic portion of the tissue. 
This leads to increased muscle competence and enhanced muscle endurance. In comparison, FR is typically a strategy as a rehabilitation aid during a workout. FR improves muscular imbalance, decreases muscle soreness effects, joint stress, improves neuromuscular performance, and improves range of motion (ROM) [2]. FR has been used in a few recovery methods and training program planning. The challenge is to decide whether SM and FR favour quicker recovery or the right DOMS reduction technique.

Physiotherapists should use a few methods such as SM, stretching and compression clothing to decrease the side effect of DOMS [5]. The science of SM has become an area of focus among the instructors, teachers, and sports physiologists of many athletes [6]. This technique is used during intense exercise for muscle-soft tissue pain and fatigue. Previous evidence has found that massage has shown beneficial benefits by minimizing body tension and other DOMS side effects [7]. Other research [8] has also shown that FR is widely used during a period of physical exercise as a rehabilitation aid. FR corrects muscle imbalances, relieves muscle discomfort and relieves joint tension. It also enhances neuromuscular performance and improves the motion range [9]. FR demonstrated a promising approach for minimizing DOMS.

However, by requiring eccentric contraction or workout with temporary muscle injury or DOMS is one of the muscle damages from physical activity. DOMS usually takes place between the first 24 hours of physical exercise and hits a peak of 24 to 72 hours [10].

\section{Research Background}

Muscle versatility, according to Massidda et al., [11], is the capacity of a muscle to lengthen or cause one joint to pass over a range of motion. Improving muscle versatility can, however, allow muscle tissue to accommodate more easily to absorb tension, enable efficient and effective movement. Due to greater muscle endurance, improving the effectiveness of action provides a beneficial impact by decreasing the chances of injury. Researchers have seen the effect of the stretching technique to restore or preserve muscle stability and prevent a reduction in the range of motion (ROM) that can hinder an individual's physical activities. Various stretching methods such as ballistic stretch, static stretch, and dynamic stretch have been used to improve muscle endurance [12]. According to them, used range of motion as a measure for the impact of stretching on endurance in 2020.

The consequence of previous studies [13-15] showed that there was no significant effect on the elbow flexion range of motion of SM and FR that prove ROM has not recovered for short term and does not have any substantial effect on it. They found that where both treatments show no beneficial effects on muscle function. Therefore, increasing blood flow to provide oxygen and other substances needed for the damaged tissue to regenerate is clearly not adequately effective by massage and FR. However only Romero-Moraleda et al., [16] found that both treatments are effective in reducing pain perception after DOMS whereas only FR application showed differences in the rectus femoris and strength.

Visual Analog Scale (VAS) is a measuring tool that seeks to quantify a trait or attitude that is assumed to extend across a meaning spectrum [17]. It is also used for assessing the severity or frequency of different symptoms in epidemiological and clinical studies [18]. The level of pain that a patient experience varies from zero to an intense amount of pain across a continuum. No pain or 4 to 5 mild pain, 5 to 7 serious pain, 7 to 10 extreme pain could be deemed to be 10-VAS scores of 0 to 4 . The results have indicated that a 33 percent reduction in pain is a fair benchmark for evaluating from the viewpoint of the patient. The percentage shift in a patient's VAS score was less biased by pre-treatment pain.

DOMS was proven significant [19] for the massage and FR situation for peak elbow flexing soreness where the severity of soreness for both therapies decreased by $20 \%$ to 40 percent. Furthermore, a review by Tiidus et al., [20] quoted by Drapper et al., [21], found that both therapies improve blood and lymph supply, increasing the reduction of pain substrates that tends to collect in the damaged region where edema is decreased. In addition, study results ([2] found that all therapies showed that the pressure-pain tolerance was lowered by DOMS. 24 and 48 hours after exercise, a significant drop in the pressure pain tolerance occurred. Reduced edema, increased blood lactate elimination, and better tissue healing are the most common pathways attributed to the rise in muscle blood supply [22].

The reduction of perceived muscle soreness by SM has been found by previous researchers [5, 23]. They endorsed this finding that SM significantly resulted in DOMS improvement. Furthermore, White et al., (2020), suggested that changes in blood and lymph flow improve the elimination of pain substrates that tend to collect in the wounded region where the edema has been decreased. The FR treatment, however, has been effective in reducing the magnitude of DOMS. Reduced edema, increased blood lactate elimination, and better tissue healing are the most common pathways attributed to the rise in muscle blood supply ([4].

The beneficial effect of SM was shown to improve skin and muscle temperature, blood and lymphatic drainage, and parasympathetic response by providing feedback. Massage, however, also has the benefits of lowering muscle stress and fatigue, decreasing muscle pain, and increasing the range of motion of the joint [24]. Therefore, massage also offers encouragement through muscle pain relief [25]. The efficacy of a 20-minute massage to suppress 24-hour DOMS is illustrated by Holub and Smith [26]. In such states, massage may be helpful for individuals 
[44] as it can decrease muscle pain following a strenuous exercise or operation. Although efficiency may not be at the standard previous to the DOMS condition, massage may have a realistic application of helping a person to handle movement better.

Myofascial release methods, such as FR and instrument-assisted soft tissue mobilization (IASTM), were used to reduce the soft tissue limitations and eventually improve ROM. FR is another approach used during vigorous exercise to alleviate DOMS. Supporters suggest FR corrects muscle imbalances, relieves muscle sores, relieving joint tension, enhances neuromas [2]. While FR has been strongly promoted and is typically a procedure [9], after an intensive exercise regimen, the effects of FR on pressure pain tolerance and dynamic performance measurements were tested, concluding that FR demonstrated a promising method of minimizing DOMS.

After post-exercise massage, researchers [19] have shown reductions in pain associated with DOMS. While there is no proof that SM specifically improves performance, it can improve flexibility and DOMS somewhat [13]. The outcomes help guide the coach and athlete about the effects of massage and inform decisions about implementing it into preparation and competition. FR by handling or avoiding soft tissue constraints is another method of technique that therapists use to help healing. Individuals only use their own body weight on a foam roller during the rolling of foam. FR can be considered as a form of self-induced massage [2]. Massage has been selected for therapy as a physiotherapeutic technique. It is commonly used to relieve DOMS psychiatric effects [19]. There are contradictory data for the use of FR after DOMS to minimize pain sensitivity. Evidence appears to support FR as a warm-up exercise rather than as a method for rehabilitation [2]. Other experiments have found that the addition of self-massage substantially increased stretch resistance and versatility [27].

Massage had no defensive effects on muscle strength and ROM, though. Systematic examination and meta-analysis found that massage intervention could be successful after strenuous exercise to relieve DOMS, as well as improve muscle performance. The results show that massage, used properly, is effective in minimizing DOMS and swelling associated with eccentric exercise. After DOMS, FR can significantly improve healing and reduce muscle tenderness. Massage may promote blood supply to regions of poor blood flow, such as the interface between muscle and tendon.

It has been shown in the previous study [28], where SM reduced the range of motion following muscle damage and for the next 4 days, ROM did not recover. In comparison, Laffaye, Torrinha Da Silva and Delafontaine [29] found that for the massaged leg, SM lowered DOMS by 50 percent compared to 20 percent for the control leg and expanded the hip range of motion for the massaged leg by approximately 4.2 percent compared to the unmassaged leg. This experiment shows the low influence of self-myofascial release on restoring the initial value of results, but after high-intensity interval training, it may be useful for reducing DOMS. However, FR also showed decreased motion range supported by previous researchers $[2,30]$ where FR losses the recovery of muscle function and swelling of the muscle. Furthermore, the increase in blood flow by rolling foam to deliver oxygen for the regeneration of damaged tissue is apparently not sufficiently effective for both treatments.

The purpose of the research is a summary of the concrete action that the researcher may take to accomplish the objective of the report. The research target for current research is as follows:

a) To identify the effect of Sports Massage (SM) and Foam Rolling (FR) on Range of Motion (ROM).

b) To identify the effect of Sports Massage (SM) and Foam Rolling (FR) on Pain Scale (PS)

\section{Materials and Methods}

Research aims to establish if SM or FR rolling is successful in reducing DOMS for participants. Almost acceptable style, but due to lack of random samples, with some control loss. In this analysis, the purposeful sampling methodology is used because the participants need to follow certain requirements. The chosen sample such as the participant is from a UTeM gym customer with 10 sample numbers and the participant must be male only with age ranging from 18 years old to 25 years old is randomly allocated to two categories in this analysis. The two categories are SM and FR. A number of UTeM gym users are included in the member draw. In a group which is SM and FR group, there have been arbitrarily assigned. All of the participants are considered to be in good physical health. In order to prevent any variations in the results, the researcher should obey the delimitation and constraint requirements as well as the guide in Table 1.

Table 1. The Delimitation and Constraint Requirements

\begin{tabular}{|c|c|}
\hline Inclusiveness & The Omission \\
\hline $\begin{array}{c}\text { The members are gym } \\
\text { users from UTeM. }\end{array}$ & $\begin{array}{c}\text { The subject has an illness that would be } \\
\text { affected during the experiment. }\end{array}$ \\
\hline $\begin{array}{c}\text { Participants may only be } \\
\text { male, }\end{array}$ & \\
\hline $\begin{array}{c}\text { Participants vary in age } \\
\text { from 18 years to } 25 \\
\text { years. }\end{array}$ & \\
\hline $\begin{array}{c}\text { Participants must be } \\
\text { healthy people. }\end{array}$ & \\
\hline
\end{tabular}

In order to produce an accurate outcome in this analysis, the specific instrumentation is used to obtain adequate measurements and to smooth the operation. Protocol of the study can be referred to Figure 1. 


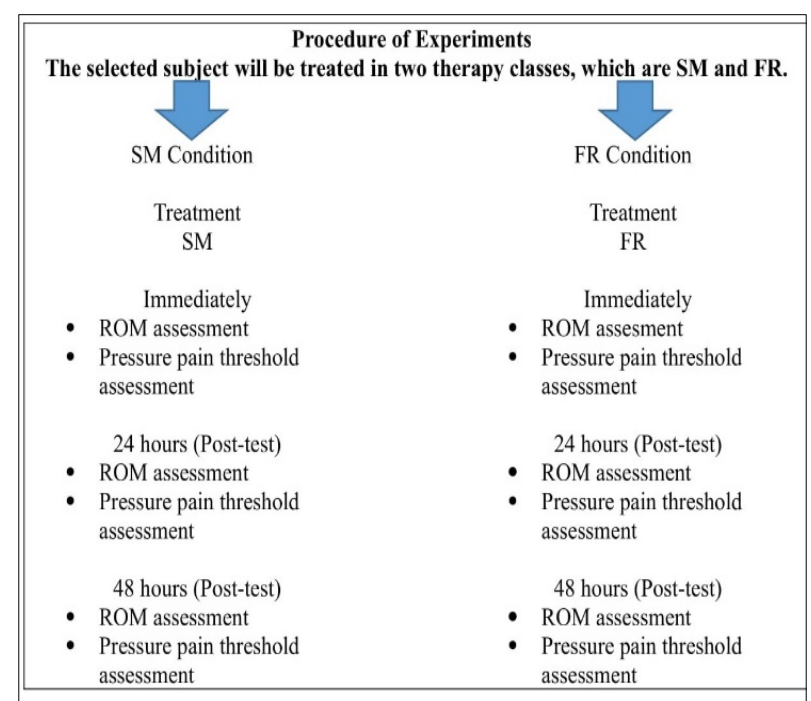

Figure 1. Protocol of Study

This massage procedure is used for intensely applied clearing techniques such as palmar and finger stroking to the skin, according to Zainuddin et al., [31], cited by Bompa and Buzzichelli [32]. When the participant laid on the massage table, massage was administered to the subject. The 10-minute massage consisted of 30 seconds of flushing of the hand, 1 minute of wrist to elbow and 1 minute of elbow to shoulder, 30 seconds of petrifying or kneading of the wrist to the elbow and 30 seconds of elbow to shoulder, 1 minute of friction to the forearm. Just 1 minute for biceps, triceps and deltoids, only 1 minute for petrissage of the wrist to the elbow and 1 minute for petrissage of the elbow to the shoulder and 30 seconds for petrissage of the hand, 1 minute for wrist to elbow, and 1 minute for elbow to shoulder.

According to Armstrong et al., [33], quoted by Reissner et al., [34], the flexed elbow of the goniometer for ROM was tested by each person. The cumulative active ROM for the elbow joint was measured using a plastic goniometer. The individual was placed on a therapy plinth in prone and supine, and the hand was shifted in flexion. To establish markers on the skin and define consistent dimensions to determine the elbow joint angle, we used a semi-permanent ink pen. These measurements consisted of the humerus' lateral epicondyle, the acromion process, and the midpoint of the ulna and radius styloid process. For each angle, there are 2 mean value measurements for the study of the calculation. In addition, with $\mathrm{r}=0.90$., the measurement reliability of the goniometer for range of motion is stated to be very high.

The visual analogue scale (VAS) is one of the most widely used pain severity scales in pain studies, according to Myles et al., (2017). Subjects were questioned when the elbow joint was forcefully flexed to mark their supposed soreness. However, the researcher indicated that no pain or 4 to 5 mild pain, 5 to 7 serious pain and 7 to 10 , extreme pain could be deemed to be 10 -VAS scores of 0 to 4 .
Based by using a percentage of the one-repetition limit (1-RM), intensity for strength training workouts is often recommended. One-RM strength is the largest amount of weight for a particular workout that a person can lift only once [35]. Several experiments have used either a generalized prediction equation [36] or prediction equations for individual exercises to produce regression equations to forecast 1-RM power [37]. It should be remembered that most of the simplified calculations are based on the exercise of the bench press [38], as it is one of the exercises done more often (Table 2).

Table 2. Upper Body Training Programmed

\begin{tabular}{c|c|c|c}
\hline Exercise & $\begin{array}{c}\text { Muscle } \\
\text { Involve }\end{array}$ & \\
Barbell Curl & Biceps & $8-12$ & 3 sets \\
Hammer Curl & Biceps & Repetition & 3 minutes' \\
1-minute rest & rest between \\
seacher Curl & Biceps & between sets & \\
Biceps Curl & Biceps & & \\
Lat pull Down & Back & & \\
\hline
\end{tabular}

The connection found for the Brzycki equation, cited by Banyard, Nosaka, and Haff [39], 1RM formula, 1RM = Weight / [1.0278-(0.0278 x number of reps)], was strong $(\mathrm{r}$ $=0.92$ ).

Get Ethical Recognition

$$
\checkmark
$$

UTEM students between the ages of 18 and 25 years who have met the requisite guidelines.

Details on the experiment to all participants and permission to sign

Upper body exercise in order to induce DOMS

First: 1RM for workout each exercise Treatment: SM

SM: 10 minutes

Markers Measure: ROM assessment and Pressure pain threshold assessment Measurement time: Immediate, 24 and 48 hours after workout

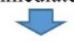

Second: 1RM for each workout exercise

Treatment: FR

FR: 20 minutes

Markers Measure: ROM assessment and Pressure pain threshold assessment Measurement time: Immediate, 24 and 48 hours after workout

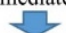

Interpretation of data and results

Figure 2. Data Collection Flow Chat

Table 3. Data Analysis

\begin{tabular}{c|c}
\hline Objectives & Data analysis \\
\hline $\begin{array}{c}\text { To identify, on three occasions, the } \\
\text { effect of SM on ROM. }\end{array}$ & Repeated Measure Anova \\
\hline $\begin{array}{c}\text { To determine the impact of SM on } \\
\text { the PS on three occasions. }\end{array}$ & Repeated Measure Anova \\
\hline $\begin{array}{c}\text { To evaluate on three occasions the } \\
\text { impact of FR on ROM. }\end{array}$ & Repeated Measure Anova \\
\hline $\begin{array}{c}\text { To determine on three occasions, the } \\
\text { effect of FR on PS. }\end{array}$ & Repeated Measure Anova \\
\hline $\begin{array}{c}\text { To identify the various benefits of } \\
\text { ROM-rolling and SM foams. }\end{array}$ & One-Way Manova \\
\hline $\begin{array}{c}\text { To assess if SM and FR have a } \\
\text { different effect on the pain threshold. }\end{array}$ & One-Way Manova \\
\hline
\end{tabular}

Statistical Package for Social Sciences (SPSS) was used to analyse data. Repeated Measure Anova and One-Way 
Manova are used to evaluate the impact of SM and FR to reduce DOMS between recreation gym users and the separate effect of SM and FR to reduce DOMS among recreation gym users (Table 3).

Ten participants between 18 and 25 years of age were split into two categories. Both patients must sign a written consent to continue with the procedure as we can see from Figure 2. In the first week of each workout, 5 members from the SM community must take their 1RM to locate their first load of each exercise. In the first week, 5 members from the SM community completed a DOMS triggered upper body exercise. Immediately after the exercise, the subject was treated as a SM for 10 minutes [5]. During surgery, two measures were taken and reported which are elbow ROM and PS using a goniometer, visual analogue scale (VAS). Over all, the next two markers were assessed at the next 24hours and 48hours without any care.

The same technique was used for the second week, but additional treatment was applied, including rest, which is foam roller therapy for 20 minutes [40]. In each fitness session, 5 participants from the FR party must take their $1 \mathrm{RM}$ of each exercise to locate their first load. In the second week, upper body exercise was done to cause DOMS by 5 participants from the FR group. Two measurements have been taken and reported using goniometer, visual analogue scale (VAS) after therapy, which are elbow ROM and PS. Over all, the next test for two markers was assessed without any care at 24hours and 48 hours, respectively.

\section{Result}

From the following table, the evidence shows that the Shapiro-Wilk value for the SM range of motion (ROM) for the three cycles immediately (ROM0hr), 24 hours post-test (ROM24h) and 48 hours post-test (ROM48h) has a substantial bending value of $0.101,0.354,0.896$. For stretching, FR has a considerable value of $0.100,0.453$, and 0.460 . Table 3 is referred. The mean value is 132.700 for the SM, ROM0hr, skewness is 1.740 and eventually 3.275 for the kurtosis. For ROM24hr, the mean value is 132.400 , and the skewness is 1390 . And then, it's 2.006 for kurtosis. The mean value for ROM48h is 132.600 , skewness is 0.427 , and finally for kurtosis is 0.238 .

If the mean value of ROM0hr is 133,700 for the FR, then $-1,694$ for the skewness and 3,515 for the kurtosis. The mean value is 133.500 for ROM24h, then -1.145 for the skewness and ultimately 2.000 for the kurtosis. The mean value is 134.100 for ROM $48 \mathrm{~h}$, then 0.593 for skewness and -1.932 for kurtosis. It can then be inferred that all the variables were distributed normally. From the table 4, the data showed that the value of Shapiro-Wilk for the PS of $\mathrm{SM}$ for the three periods which are immediately (PSOhr), 24 hours post-test (PS24hr) and 48 hours post-test (PS48hr) has significant value of $0.006,0.006,0.006$ for flexion. FR has significant value of $0.134,0.006,0.006$ for flexion.

Table 4. Shapiro-wilk for Range of Motion (ROM) elbow flexion of SM and FR group.

\begin{tabular}{|c|c|c|c|c|c|c|}
\hline \multirow{2}{*}{ Variable } & \multicolumn{3}{|c|}{ Shapiro Wilk } & \multirow{2}{*}{ Mean } & \multirow{2}{*}{ Skewness } & \multirow{2}{*}{ Kurtosis } \\
\hline & Statistic & Df & Sig. & & & \\
\hline \multicolumn{6}{|l|}{ SM } & \multirow{4}{*}{$\begin{array}{l}3.275 \\
2.006 \\
0.238\end{array}$} \\
\hline ROM0hr & 0.812 & 5 & 0.101 & 132.700 & 1.740 & \\
\hline ROM24hr & 0.889 & 5 & 0.354 & 132.400 & 1.390 & \\
\hline ROM48hr & 0.973 & 5 & 0.896 & 132.600 & 0.427 & \\
\hline \multicolumn{7}{|l|}{ FR } \\
\hline ROM0hr & 0.812 & 5 & 0.100 & 133.700 & -1.694 & 3.515 \\
\hline ROM24hr & 0.908 & 5 & 0.453 & 133.500 & -1.145 & 2.000 \\
\hline ROM48h & 0.909 & 5 & 0.460 & 134.100 & 0.593 & -1.932 \\
\hline
\end{tabular}


The mean value is 6.60 for the SM, PCOhr, the skewness is -0.609 and eventually -3.333 for the kurtosis. The mean value for $\mathrm{PC} 24 \mathrm{~h}$ is 4.40 , the skewness is 0.609 , and eventually for kurtosis is -3.333 . The mean value for PC $48 \mathrm{hr}$ is 3.60 , the skewness is -0.609 , and essentially for kurtosis is -3.333 . Whereas the mean value is 6.80 for the FR, PCOhr, then 0.512 for the skewness and -0.612 for the kurtosis. For PC24hr, the mean value is 6.40 , so 0.609 for the skewness, and -3.333 for the kurtosis. The mean value is 4.60 for PC $48 \mathrm{hr}$, then -0.609 for the skewness and finally -3.333 for the kurtosis. It can then be inferred that all the variables were distributed normally (Table 5).

Table 5. Shapiro-wilk for PS elbow flexion of SM and FR

\begin{tabular}{ccccccc}
\hline \multirow{2}{*}{ Variable } & \multicolumn{3}{c}{ Shapiro Wilk } & & \\
\cline { 2 - 4 } & Statistic & Df & Sig. & & & Kean \\
SM & & & & & & \\
\hline PS0hr & 0.684 & 5 & 0.006 & 6.60 & -0.609 & -3.333 \\
PS24hr & 0.684 & 5 & 0.006 & 4.40 & 0.609 & -3.333 \\
PS48hr & 0.684 & 5 & 0.006 & 3.60 & -0.609 & -3.333 \\
& & & & & & \\
FR & & & & & & \\
PS0hr & 0.881 & 5 & 0.314 & 6.80 & 0.512 & -0.612 \\
PS24hr & 0.684 & 5 & 0.006 & 6.40 & 0.609 & -3.333 \\
PS48hr & 0.684 & 5 & 0.006 & 4.60 & -0.609 & -3.333 \\
\hline
\end{tabular}

The measure is used from the table above (Table 6) to access the elbow Range of Motion (ROM) contact effect for flexion over two separate therapy units. The findings of all subject-effect experiments were the same, but the Greenhouse-Geisser numbers were the most widely recorded. As seen above, for flexion 0.801 , which is greater than alpha level $0.05(\mathrm{p}<0.05)$, the association effect for $\mathrm{SM}$ is not statically relevant. Since the $\mathrm{p}$ value is greater than 0.05 , it can be inferred that no effect between therapies was statically important.

Table 6. Comparison effect of SM and FR therapy on elbow

\begin{tabular}{ccccc}
\hline $\begin{array}{c}\text { Effect } \\
(\text { ROM })\end{array}$ & & F & Sig. & $\begin{array}{c}\text { Eta } \\
\text { Squared }\end{array}$ \\
\hline SM & Flexion & 0.228 & 0.801 & 0.054 \\
FR & Flexion & 0.314 & 0.639 & 0.073 \\
\hline
\end{tabular}

The key result, however, was not significant, with a value of 0.801 greater than alpha level $0.05(\mathrm{p}<0.05)$, so that there was no change in ROM between treatments over three different periods of time. Greenhouse-Geisser stated for flexion $\mathrm{F}=0.228, \mathrm{p}=0.801$, eta squared $=0.054$ that there is no substantial correlation between the treatment and Range of Motion. In order to endorse and improve the findings, the impact scale of this finding is also measured. The effect size was taken from the eta squared value, resulting in a small effect size of the value received for bending 0.054 .

The measure is used from the table 6 to access the elbow Range of Motion (ROM) contact effect for flexion over two separate therapy units. The findings of all subject-effect experiments were the same, but the
Greenhouse-Geisser numbers were the most widely recorded. As seen above, for flexion 0.639 , which is more than alpha level 0.05 , the association effect for FR is not statically important $(\mathrm{p}<0.05)$. Since the $\mathrm{p}$ value is greater than 0.05 , it can be inferred that no effect between therapies was statically important.

The key result, however, was not important, with a value of 0.639 greater than alpha level $0.05(p<0.05)$, so that there was little difference in ROM between treatments over three different periods of time. Greenhouse-Geisser stated for flexion $\mathrm{F}=0.314, \mathrm{p}=0.639$, eta squared $=0.073$ that there is no major correlation between the treatment and Range of Motion. In order to endorse and improve the findings, the impact scale of this finding is also measured. The effect size was taken from the eta squared value, resulting in a mild effect size of the value obtained for bending 0.073.

It revealed the distinct three-time intervals of ROM flexion based on a pairwise comparison table below (Table 7). All the variations were not statically important in this table, where the p-value was more than 0.05 . There was no meaning between instantly (ROM0hr) and 24hours (ROM24hr) since there were a huge number of 0.300 separate ROM shifts.

Table 7. Pairwise Comparison SM on three-time intervals of ROM flexion

\begin{tabular}{cccc}
\hline \multirow{2}{*}{ (I) ROM } & (J) ROM & $\begin{array}{c}\text { Mean } \\
\text { Difference } \\
(\mathrm{I}-\mathrm{J})\end{array}$ & Sig. \\
\hline \multirow{2}{*}{ Immediately } & $24 \mathrm{~h}$ & 0.300 & 1.000 \\
& $48 \mathrm{~h}$ & 0.100 & 1.000 \\
\hline \multirow{2}{*}{$24 \mathrm{~h}$} & immediately & -0.300 & 1.000 \\
& $48 \mathrm{~h}$ & -0.200 & 1.000 \\
\hline \multirow{2}{*}{$48 \mathrm{~h}$} & immediately & -0.100 & 1.000 \\
& $24 \mathrm{~h}$ & 0.200 & 1.000 \\
\hline
\end{tabular}

Note: ${ }^{*} \mathrm{p}<0.05$

At Table 8, it revealed the distinct three-time intervals of ROM flexion based on a pairwise comparison table (Table 8). All the variations were not statically significant in this table, where the p-value was more than 0.05 . Between 48 hours (ROM48hr) and 24 hours (ROM24hr) it was not important because there were a vast number of separate ROM changes that were 0.600 .

Table 8. Pairwise Comparison FR on Three-Time Intervals of ROM Flexion

\begin{tabular}{cccc}
\hline (I) ROM & (J) ROM & $\begin{array}{c}\text { Mean } \\
\text { Difference } \\
\text { (I-J) }\end{array}$ & Sig. \\
\hline Immediately & $24 \mathrm{~h}$ & 0.200 & 1.000 \\
& $48 \mathrm{~h}$ & -0.400 & 1.000 \\
\hline \multirow{2}{*}{$24 \mathrm{~h}$} & immediately & -0.200 & 1.000 \\
& $48 \mathrm{~h}$ & -0.600 & 1.000 \\
\hline \multirow{2}{*}{$48 \mathrm{~h}$} & immediately & 0.400 & 1.000 \\
& $24 \mathrm{~h}$ & 0.600 & 1.000 \\
\hline
\end{tabular}

In order to evaluate the effect of two different treatments (SM, FR) on the elbow range of motion (ROM) for elbow 
flexion among recreational gym users, a single-way Manova subject analysis of multivariate tests was conducted. The significance value for the flexion is 0.890 from the above data (Table 9), which means that the value is not significant above the alpha stage of 0.05 . The main effect comparing the two types of treatment for ROM flexion was $\mathrm{F}=0.204, \mathrm{P}=0.890$, eta squared $=0.093$, reported by Wilks' lambda.

Table 9. Effect of SM and FR on ROM

\begin{tabular}{cccccc}
\hline Effect & & Value & F & Sig. & $\begin{array}{c}\text { Eta } \\
\text { Squared }\end{array}$ \\
\hline ROM & Flexion & 0.907 & 0.204 & 0.890 & 0.093 \\
\hline
\end{tabular}

Note: ${ }^{*} \mathrm{p}<0.05$

The measure is used from the table below (Table 10) to access the elbow PS contact effect for flexion over two separate therapy units. The findings of all subject-effect experiments were the same, but the Greenhouse-Geisser numbers were the most widely recorded. As seen above, for flexion 0.000, which is smaller than alpha level 0.05, the association effect for SM is statically important $(\mathrm{p}<0.05)$. Although the $\mathrm{p}$ value is less than 0.05 , it can be inferred that the results between therapies were statically significant.

Table 10. Comparison effect of SM and FR therapy on PS

\begin{tabular}{clccc}
\hline $\begin{array}{c}\text { Effect } \\
\text { (PS) }\end{array}$ & & F & Sig. & $\begin{array}{c}\text { Eta } \\
\text { Squared }\end{array}$ \\
\hline SM & Flexion & 51.714 & 0.000 & 0.928 \\
FR & Flexion & 58.857 & 0.000 & 0.936 \\
\hline
\end{tabular}

The key result, however, was positive, with a value of 0.000 lower than alpha level $0.05(\mathrm{p}<0.05)$, meaning that it may be stated that there was a shift in PS over the three separate cycles between therapies. Both the treatment and the PS, Greenhouse-Geisser for flexion $F=51.714, p=0.000$, eta squared $=0.928$, there was a major relationship. In order to endorse and improve the findings, the impact scale of this finding is also measured. The effect size was taken from the eta squared value, so that the effect size obtained for PS flexion 0.928 is small.

Table 11. Pairwise Comparison SM on Three-Time Intervals of PS Flexion

\begin{tabular}{cccc}
\hline \multirow{2}{*}{ (I) PS } & (J) PS & $\begin{array}{c}\text { Mean } \\
\text { Difference } \\
\text { (I-J) }\end{array}$ & Sig. \\
\hline \multirow{2}{*}{ Immediately } & $24 \mathrm{~h}$ & 2.200 & 0.013 \\
& $48 \mathrm{~h}$ & 3.000 & 0.002 \\
\hline \multirow{2}{*}{$24 \mathrm{~h}$} & Immediately & -2.200 & 0.013 \\
& $48 \mathrm{~h}$ & 0.800 & 0.048 \\
\hline \multirow{2}{*}{$48 \mathrm{~h}$} & Immediately & -3.000 & 0.002 \\
& $24 \mathrm{~h}$ & -0.800 & 0.048 \\
\hline
\end{tabular}

Note: ${ }^{*} \mathrm{p}<0.05$

It displayed the various three-time intervals of PS flexion on the basis of a pairwise comparison table (Table 11). All the variations in this table were statically important, where the p-value was less than 0.05. There was a significant time between instantly (PSOhr) and 48 hours (PS48hr) when there were a huge number of PS improvements that were 3,000.

The key result, however, was significant, with a value of 0.000 lower than alpha level $0.05(\mathrm{p}<0.05)$, meaning that it may be stated that there was a shift in PS over the three separate cycles between therapies. For flexion $\mathrm{F}=58.857, \quad \mathrm{p}=0.000, \quad$ eta $\quad$ squared $=0.936$, Greenhouse-Geisser registered a substantial relationship between the treatment and Range of Motion. In order to endorse and improve the findings, the impact scale of this finding is also measured. The effect size was taken from the eta squared value, so that the effect size obtained for PS flexion 0.936 is mild.

It revealed the distinct four-time intervals of PS flexion based on a pairwise comparison table below (Table 12). All the variations in this table were statically significant, where the $\mathrm{p}$-value was less than 0.05 . There was a wide range between instantly (PSOhr) and 48 hours (PS48hr) since there were a huge number of separate PS shifts, which was 2,000 .

Table 12. Pairwise Comparison FR on three-time intervals of PS flexion

\begin{tabular}{cccc}
\hline \multirow{2}{*}{ (I) PS } & (J) PS & $\begin{array}{c}\text { Mean } \\
\text { Difference } \\
\text { (I-J) }\end{array}$ & Sig. \\
\hline \multirow{2}{*}{ Immediately } & $24 \mathrm{~h}$ & 0.400 & 0.533 \\
& $48 \mathrm{~h}$ & 2.000 & 0.001 \\
\hline \multirow{2}{*}{$24 \mathrm{~h}$} & Immediately & -0.400 & 0.533 \\
& $48 \mathrm{~h}$ & 1.800 & 0.003 \\
\hline \multirow{2}{*}{$48 \mathrm{~h}$} & Immediately & -2.200 & 0.001 \\
& $24 \mathrm{~h}$ & -1.800 & 0.003 \\
\hline
\end{tabular}

Note: ${ }^{*} \mathrm{p}<0.05$

To determine the effect of two separate therapies (SM, FR) on the elbow PS for elbow flexion among casual gym users, a One-Way Manova topic study of multivariate tests was performed. The meaningful value for the flexion is 0.011 from the above results (Table 13), indicating that the value is significant less than the alpha amount of 0.05 . The key influence comparing the two forms of treatment for PS flexion was $\mathrm{F}=9.321, \mathrm{P}=0.011$, eta squared $=0.823$, stated by Wilks' lambda.

Table 13. Effect of SM and FR on PS

\begin{tabular}{cccccc}
\hline Effect & & Value & F & Sig. & $\begin{array}{c}\text { Eta } \\
\text { Squared }\end{array}$ \\
\hline PS & Flexion & 0.177 & 9.321 & 0.011 & 0.823 \\
\hline
\end{tabular}

\section{Discussion, Conclusion \& Recommendation}

The goal of this research is to ascertain the efficacy of two therapies, SM and FR, in order to minimize DOMS among users of recreational gyms. As a player of sports 
science industry, knowledge regarding all of this techniques is really advisable [45]. The procedure that can be used to improve the athlete's healing process is usually SM and FR exercise. Two biomarkers in the body, ROM and PS, may be affected by these procedures. In addition, these medications minimize DOMS, which typically happens following strenuous training or repeated exercise. In this segment, there are three sections that comprise the debate, conclusion, and recommendations. The results and conclusions of the current study will be presented in the discussion section. The ultimate hypothesis for this research will be addressed in the conclusion section.

The measure is used from the table above to access the elbow Range of Motion (ROM) contact effect for flexion over two separate therapy units. The relationship effect for SM and FR is not statically significant for flexion 0.801 , 0.639 , which is more than alpha level 0.05 ( $\mathrm{p}<0.05$ ), as seen above, based on the present outcome. Since the $p$ value is greater than 0.05 , it can be inferred that no effect between therapies was statically important. The key result, however, was not significant, with a value of $0.801,0.639$ greater than alpha level $0.05(\mathrm{p}<0.05)$, so that there was no difference in ROM between treatments over three different periods of time. There was a report from the previous research which confirms this current study. There is, however, a lack of studies about the range of motion of casual gym users.

The consequence of this current study showed that there was no significant effect on the elbow flexion range of motion of SM and FR. This is similar to previous studies $[19,41]$, who report that ROM has not recovered for short term and does not have any substantial effect on it. These findings, in turn, are also similar to previous studies $[13,14]$, where both treatments show no beneficial effects on muscle function. Therefore, increasing blood flow to provide oxygen and other substances needed for the damaged tissue to regenerate is clearly not adequately effective by massage and FR. However previous study [16] found that both treatments are effective in reducing pain perception after DOMS whereas only FR application showed differences in the rectus femoris and strength.

The test is used to access the elbow PS touch impact with flexion over two different treatment units. Based on the present result, the correlation effect for SM and FR is statically relevant for bent $0.000,0.000$, which is less than alpha level $0.05(\mathrm{p}<0.05)$, as seen above. Because the $\mathrm{p}$ value is less than 0.05 , it can be concluded that the effects were statically relevant between treatments. However, with a value of $0.000,0.000$ lower than alpha level 0.05 , the main finding was important $(\mathrm{p}<0.05)$, because there was a change in the PS between procedures over three different periods of time. A paper from prior studies has been released that supports this new analysis. However, there is a lack of research on the range of motion of regular members of the gym.

In this current research DOMS was significant $[19,41]$ for the SM and FR situation for peak elbow flexing soreness where, the severity of soreness for both therapies decreased by $20 \%$ to 40 percent. Furthermore, a review $[20,21]$, found that both therapies improve blood and lymph supply, increasing the reduction of pain substrates that tend to collect in the damaged region where edema is decreased. In addition, study results [2] found that all therapies showed that the pressure-pain tolerance was lowered by DOMS. 24 and 48 hours after exercise, a significant drop in the pressure pain tolerance occurred. Reduced edema, increased blood lactate elimination, and better tissue healing are the most common pathways attributed to the rise in muscle blood supply [22, 2].

Based on the present outcome, it was found that both treatments could not change the ROM over the three-fold duration in which the significant value was 0.890 , hence more than the alpha standard of 0.05 . This outcome revealed that there was no significant correlation between the medication and the range of motion. In addition, Wilks' lambda reported that the main effect of comparing the two types of treatment for ROM flexion was $\mathrm{F}=0.204$, $\mathrm{P}=0.890$, eta squared $=0.093$ and revealed that there was no distinct effect in the range of motion for both therapies.

It has been shown in the current study that there is no significant interaction between the treatment and the range of motion. This is similar to the previous studies $[28,15]$, where SM reduced the range of motion following muscle damage and for the next 4 days, ROM did not recover. In comparison, found that for the massaged leg, SM lowered DOMS by 50 percent compared to 20 percent for the control leg and expanded the hip range of motion for the massaged leg by approximately 4.2 percent compared to the unmassaged leg [29]. This experiment shows the low influence of self-myofascial release on restoring the initial value of results, but after high-intensity interval training, it may be useful for reducing DOMS.

FR, however, also showed decreased motion range supported by previous researcher [2], where FR losses the recovery of muscle function and swelling of the muscle. Furthermore, the increase in blood flow by rolling foam to deliver oxygen for the regeneration of damaged tissue is apparently not sufficiently effective for both treatments.

In recent findings, both therapies showed a decrease in perceived muscle soreness, which is the level of PS that showed the amount to be 0.011 , lower than the alpha value. This value indicated that a significant interaction existed between the treatments and the level of pain. Wilks' lambda, however, reported that the main effect of comparing the two types of PS flexion treatment was $\mathrm{F}=$ 9.321, $\mathrm{P}=0.011$, eta squared $=0.823$ and revealed that both therapies have different effects in the range of motion.

Based on current findings, it showed that the outcome was comparable with previous research, which is the reduction of perceived muscle soreness by SM. Previous researchers $[23,5]$, endorsed this finding that SM therapy 
significantly resulted in DOMS improvement. Furthermore, there are some suggestions [42,43] that changes in blood and lymph flow improve the elimination of pain substrates that tend to collect in the wounded region where the edema has been decreased. The FR treatment, however, has been effective in reducing the magnitude of DOMS. Reduced edema, increased blood lactate elimination, and better tissue healing are the most common pathways attributed to the rise in muscle blood supply $([4,16]$.

Study compared SM and FR on DOMS finds out no major main impact on range of motion for either therapy. Significant main effect for both PS therapies. Both therapies can be used to reduce DOMS, according to the study. The range of motion for elbow flexion is the same for both therapies. Null hypothesis for the impact of SM and FR on the range of motion was not rejected. Null hypothesis was also not rejected for the differing effect on the PS for both therapies. The researcher obtained a lot of feedback, expertise and experience as well as the investigative evidence.

The researcher has come up with a couple of recommendations:

a) This research was restricted to the male population of recreational gym users aged 18-25. Future studies can extend to female communities

b) More on the right form of massage will be learned in future studies and there were several recommendations about the styles of massage.

c) More scientific research on the effects of SM and FR on DOMS.

\section{Acknowledgements}

Authors are grateful to Universiti Malaysia Sabah that this study is supported by the university internal allocation and research grant.

\section{REFERENCES}

[1] Moran, R. N., Hauth, J. M., \& Rabena, R. (2018). The effect of massage on acceleration and sprint performance in track \& field athletes. Complementary therapies in clinical practice, $30,1-5$.

[2] Wilke, J., Müller, A. L., Giesche, F., Power, G., Ahmedi, H., \& Behm, D. G. (2020). Acute Effects of Foam Rolling on Range of Motion in Healthy Adults: A Systematic Review with Multilevel Meta-analysis. Sports medicine (Auckland, N.Z.), 50(2), 387-402. https://doi.org/10.1007/s40279-01901205-7

[3] Wiewelhove, T., Döweling, A., Schneider, C., Hottenrott, L., Meyer, T., Kellmann, M., ... \& Ferrauti, A. (2019). A meta-analysis of the effects of foam rolling on performance and recovery. Frontiers in physiology, 10, 376.
[4] Adamczyk, J. G., Gryko, K., \& Boguszewski, D. (2020). Does the type of foam roller influence the recovery rate, thermal response and DOMS prevention? PloS one, 15(6), $\mathrm{e} 0235195$.

[5] Dupuy, O., Douzi, W., Theurot, D., Bosquet, L., \& Dugué, B. (2018). An evidence-based approach for choosing post-exercise recovery techniques to reduce markers of muscle damage, soreness, fatigue, and inflammation: a systematic review with meta-analysis. Frontiers in Physiology, 9, 403.

[6] Kayacan, Y., Kaya, Y. and Makarac1, Y., 2017. Excretion of creatinine, uric acid and microproteins by general body massage applied after exercise. European Journal of Physical Education and Sport Science.

[7] Nadal-Nicolás, Y., Rubio-Arias, J. Á., Martínez-Olcina, M., Reche-García, C., Hernández-García, M., \& Martínez-Rodrí guez, A. (2020). Effects of Manual Therapy on Fatigue, Pain, and Psychological Aspects in Women with Fibromyalgia. International Journal of Environmental Research and Public Health, 17(12), 4611.

[8] Henning, Carley J. "The acute effect of foam rolling on range of motion, flexibility, agility, and vertical jump height." $\mathrm{PhD}$ diss., 2019.

[9] Sandrey, M. A., Lancellotti, C., \& Hester, C. (2020). The Effect of Foam Rolling Versus IASTM on Knee Range of Motion, Fascial Displacement, and Patient Satisfaction. Journal of Sport Rehabilitation, 1(aop), 1-8.

[10] Brandner, Christopher R., and Stuart A. Warmington. "Delayed onset muscle soreness and perceived exertion after blood flow restriction exercise." The Journal of Strength \& Conditioning Research 31, no. 11 (2017): 3101-3108.

[11] Massidda, M., Miyamoto, N., Beckley, S., Kikuchi, N., \& Fuku, N. (2019). Genetics of flexibility. In Sports, Exercise, and Nutritional Genomics (pp. 273-293). Academic Press.

[12] Rahman, Md Hamidur, and Muhammad Shahidul Islam. "Stretching And Flexibility: A Range Of Motion For Games And Sports." European Journal of Physical Education and Sport Science 6, no. 8 (2020).

[13] Davis, H. L., Alabed, S., \& Chico, T. J. A. (2020). Effect of sports massage on performance and recovery: a systematic review and meta-analysis. BMJ Open Sport \& Exercise Medicine, 6(1), e000614.

[14] Kyranoudis, A., Arsenis, S., Ispyrlidis, I., Chatzinikolaou, A., Gourgoulis, V., Kyranoudis, E., \& Metaxas, T. (2019). The acute effects of combined foam rolling and static stretching program on hip flexion and jumping ability in soccer players. Journal of Physical Education and Sport, 19(2), 1164-1172

[15] Macgregor, L.J., Fairweather, M.M., Bennett, R.M. et al. The Effect of Foam Rolling for Three Consecutive Days on Muscular Efficiency and Range of Motion. Sports Med Open 4, 26 (2018). https://doi.org/10.1186/s40798-018-014 $1-4$

[16] Romero-Moraleda, B., La Touche, R., Lerma-Lara, S., Ferrer-Peña, R., Paredes, V., Peinado, A. B., \& Muñoz-García, D. (2017). Neurodynamic mobilization and foam rolling improved delayed-onset muscle soreness in a healthy adult population: a randomized controlled clinical trial. PeerJ, 5, e3908. 
[17] Kalinsky, E. B., Chernyaev, A. V., Slinyakov, L. Y., Lychagin, A. V., \& Kalinsky, B. M. (2018). Clinical and radiographic characteristics of patients with cervicalgia after previous injury to the pectoral girdle. Bulletin of Russian State Medical University, (2).

[18] Matejka, J., Glueck, M., Grossman, T., \& Fitzmaurice, G. (2016, May). The effect of visual appearance on the performance of continuous sliders and visual analogue scales. In Proceedings of the 2016 CHI Conference on Human Factors in Computing Systems (pp. 5421-5432).

[19] Poppendieck, W., Wegmann, M., Ferrauti, A., Kellmann, M., Pfeiffer, M., \& Meyer, T. (2016). Massage and performance recovery: a meta-analytical review. Sports medicine, 46(2), 183-204.

[20] Tiidus, P. M., \& Shoemaker, J. K. (1995). Effleurage massage, muscle blood flow and long-term post-exercise strength recovery. International journal of sports medicine, 16(07), 478-483.

[21] Draper, S. N., Kullman, E. L., Sparks, K. E., Little, K., \& Thoman, J. (2020). Effects of Intermittent Pneumatic Compression on Delayed Onset Muscle Soreness (DOMS) in Long Distance Runners. International Journal of Exercise Science, 13(2), 75.

[22] Yanaoka, T., Yoshimura, A., Iwata, R., Fukuchi, M., \& Hirose, N. (2020). The effect of foam rollers of varying densities on range of motion recovery. Journal of Bodywork and Movement Therapies.

[23] Bender, P. U., da Luz, C. M., Feldkircher, J. M., \& Nunes, G. S. (2019). Massage therapy slightly decreased pain intensity after habitual running, but had no effect on fatigue, mood or physical performance: a randomised trial. Journal of physiotherapy, 65(2), 75-80.

[24] Hartono, S., Widodo, A., Wismanadi, H., \& Hikmatyar, G. (2019). The effects of roller massage, massage, and ice bath on lactate removal and delayed onset muscle soreness. Sport Mont, 17(2), 111-114.

[25] Yoon, W. Y., Lee, K., \& Kim, J. (2020). Curcumin supplementation and delayed onset muscle soreness (DOMS): effects, mechanisms, and practical considerations. Physical Activity and Nutrition, 24(3), 39-43.

[26] Holub, C., \& Smith, J. D. (2017). Effect of Swedish massage on DOMS after strenuous exercise. International Journal of Exercise Science, 10(2), 258-265.

[27] Capobianco, R. A., Mazzo, M. M., \& Enoka, R. M. (2019). Self-massage prior to stretching improves flexibility in young and middle-aged adults. Journal of sports sciences, 37(13), 1543-1550.

[28] Yoshimura, A., Schleip, R., \& Hirose, N. (2020). Effects of Self-Massage Using a Foam Roller on Ankle Range of Motion and Gastrocnemius Fascicle Length and Muscle Hardness: A Pilot Study. Journal of Sport Rehabilitation, 1(aop), 1-8.

[29] Laffaye, G., Torrinha Da Silva, D., \& Delafontaine, A. (2019). Self-myofascial release effect with foam rolling on recovery after high-intensity interval training. Frontiers in Physiology, 10, 1287.
[30] Madoni, S. N., Costa, P. B., Coburn, J. W., \& Galpin, A. J. (2018). Effects of foam rolling on range of motion, peak torque, muscle activation, and the hamstrings-to-quadriceps strength ratios. The Journal of Strength \& Conditioning Research, 32(7), 1821-1830.

[31] Zainuddin, Z., Newton, M., Sacco, P., \& Nosaka, K. (2005). Effects of massage on delayed-onset muscle soreness, swelling, and recovery of muscle function. Journal of athletic training, 40(3), 174.

[32] Bompa, T. O., \& Buzzichelli, C. (2018). Periodization-: theory and methodology of training. Human kinetics.

[33] Armstrong, A. D., MacDermid, J. C., Chinchalkar, S., Stevens, R. S., \& King, G. J. (1998). Reliability of range-of-motion measurement in the elbow and forearm. Journal of shoulder and elbow surgery, 7(6), 573-580.

[34] Reissner, L., Fischer, G., List, R., Taylor, W. R., Giovanoli, P., \& Calcagni, M. (2019). Minimal detectable difference of the finger and wrist range of motion: comparison of goniometry and 3D motion analysis. Journal of orthopaedic surgery and research, 14(1), 173.

[35]Fleck, S. J., \& Kraemer, W. J. (2017). Fundamentos do treinamento de força muscular. Artmed Editora.

[36] Van Den Tillaar, R., \& Ball, N. (2020). Push-Ups are Able to Predict the Bench Press 1-RM and Constitute an Alternative for Measuring Maximum Upper Body Strength Based on Load-Velocity Relationships. Journal of Human Kinetics, 73(1), 7-18.

[37] Moneghetti, K. J., Hock, J., Kaminsky, L., Arena, R., Lui, G. K., Haddad, F., ... \& Christle, J. W. (2018). Applying current normative data to prognosis in heart failure: The Fitness Registry and the Importance of Exercise National Database (FRIEND). International Journal of Cardiology, 263, 75-79.

[38] García-Ramos, A., Suzovic, D., \& Pérez-Castilla, A. (2019). The load-velocity profiles of three upper-body pushing exercises in men and women. Sports Biomechanics, 1-13.

[39] Banyard, H. G., Nosaka, K., \& Haff, G. G. (2017).

[40] Soe, S. P., P. Martin, M. Jones, M. Robinson, and Peter Theobald. "Feasibility of optimising bicycle helmet design safety through the use of additive manufactured TPE cellular structures." The International Journal of Advanced Manufacturing Technology 79, no. 9-12 (2015): 1975-1982.

[41] Kargarfard, M., Lam, E. T., Shariat, A., Shaw, I., Shaw, B. S., \& Tamrin, S. B. (2016). Efficacy of massage on muscle soreness, perceived recovery, physiological restoration and physical performance in male bodybuilders. Journal of sports sciences, 34(10), 959-965.

[42] White, G. E., West, S. L., Caterini, J. E., Battista, A. P. D., Rhind, S. G., \& Wells, G. D. (2020). Massage Therapy Modulates Inflammatory Mediators Following Sprint Exercise in Healthy Male Athletes. Journal of Functional Morphology and Kinesiology, 5(1), 9.

[43] Hunt, E. R., Confides, A. L., Abshire, S. M., Dupont Versteegden, E. E., \& Butterfield, T. A. (2019). Massage increases satellite cell number independent of the age associated alterations in sarcolemma permeability. Physiological reports, 7(17), e14200. 
[44] Bambang Priyonoadi, Japhet Ndayisenga, Panggung Sutopo, Ali Satia Graha, "Immunoglobulin-A (IgA) Improvement through Sports and Frirage Massage," International Journal of Human Movement and Sports Sciences, Vol. 8, No. 5, pp. 271-282, 2020. DOI: 10.13189/saj.2020.080516
[45] Yustinus Sukarmin, Japhet Ndayisenga, "Evaluation of Burundi Physical Education Teachers, Coaches, and Athletes' Sport Nutrition, Massage, and Physiotherapeutic Exercises Knowledge," International Journal of Human Movement and Sports Sciences, Vol. 8, No. 4, pp. 154 - 159, 2020. DOI: 10.13189/saj.2020.080408. 